\title{
EARLY FUNCTIONAL RESULTS OF UNSTABLE PERTROCHANTERIC FRACTURES TREATED WITH PROXIMAL FEMORAL NAILS IN A PERIPHERAL TERTIARY CARE CENTRE
}

\author{
R. J. Bharat Kumar ${ }^{1}$, Victor Moirangthem², M. Narayana Reddy ${ }^{3}$
}

\section{HOW TO CITE THIS ARTICLE:}

R. J. Bharat Kumar, Victor Moirangthem, M. Narayana Reddy. "Early Functional Results of Unstable Pertrochanteric Fractures Treated with Proximal Femoral Nails in a Peripheral Tertiary Care Centre". Journal of Evolution of Medical and Dental Sciences 2015; Vol. 4, Issue 43, May 28; Page: 7513-7519, DOI: $10.14260 /$ jemds/2015/1090

ABSTRACT: BACKGROUND: Pertrochanteric fractures forms a major share of proximal femoral fractures in young and old. Proper implant selection and surgical planning plays a pivotal role in providing fracture union and early rehabilitation of patients to prevent complications due to recumbency. AIM: The aim of this retrospective study is to assess the results of proximal femoral nails in unstable pertrochanteric fractures. MATERIALS AND METHODS: This study was performed in the Department of Orthopaedic Surgery, Chettinad hospital and research institute, Kelambakkam between November 2012 and December 2014. 15 patients with pertrochanteric fractures were retrospectively followed. Among the fifteen 9 were male and 6 were female with an average age of 43 . Eleven patients sustained Intertrochanteric fractures, 8 of A2 type and 3 of A3 type according to AO classification. 4 patients had subtrochanteric fractures of seinseimer Type 5. RESULTS: Short PFN was used in all the 11 Intertrochanteric fractures and long PFN was used in the 4 subtrochanteric fractures. All fractures healed by around 3.5 months. There is one case of varus malunion and one case of screw pullout which required implant removal. The limitations of this study are its retrospective nature, small sample size and short follow up. CONCLUSION: Our results show that proximal femoral nails being load sharing implants form an ideal choice for stabilising pertrochanteric fractures. Minimally invasive technique of insertion with less blood loss make it an ideal choice in such complex scenarios.

KEYWORDS: Pertrochanteric unstable fractures, Proximal femoral nails, Stability.

INTRODUCTION: Pertrochanteric fractures are one among the commonly encountered fractures in clinical orthopaedic practice particularly in geriatric population.1,2,3 Increasing age and associated comorbities like osteoporosis, makes the geriatric group more vulnerable to these fractures. High energy trauma due to RTA and fall from height, constitute the bulk of young patients who sustain pertrochanteric fractures. Treatment of pertrochanteric fractures have evolved over time from extramedullary fixation devices to newer intramedullary fixation devices. ${ }^{4}$ Biomechanical studies have shown intramedullary nails to be more stable load sharing devices compared to load bearing extramedullary devices. Although technical issues still harbour over their usage, they outweigh some of their advantages, like immediate partial weight bearing, minimally invasive technique of insertion, minimal blood loss, minimal soft tissue dissection ${ }^{5}$ and short operating time.

We retrospectively studied 15 unstable pertrochanteric fractures treated with proximal femoral nails for perioperative outcomes and post operative functional recovery.

MATERIALS AND METHODS: We retrospectively evaluated 15 of our patients treated for unstable pertrochanteric fractures with proximal femoral nailing at our institution which is a tertiary care 
centre between 2012 and 2014. Among the 15 patients, 9 were male and 6 were females in the age group between 25 to 62 with an average of 43 years. 7 of them were due to simple fall and 8 due to RTA. 11 patients sustained Intertrochanteric fractures, 8 of A2 type and 3 of A3 type according to AO classification. 4 patients had subtrochanteric fractures of seinseimer Type 5. 10 were on the right side and 5 on the left side. Three dimenstional CT imaging was done particularly for subtrochanteric fractures to assess the level of communition and entry point at the greater trochanter.

All fifteen patients underwent proximal femoral nails after informed consent. Patients were made to do high sit ups, isometric quadriceps excercises and deep breathing excercises on day one of surgery. Knee range of movements started by day 2 and partial bearing mobilisation with walker support was started by day 3 or 4 depending on the confidence level of the patient. Follow up radiographs were taken by 6 weeks, 3 months and 6 months period to assess bony union and implant related complications. At each followup patients were assessed for local wound status, pain, ambulation, knee and hip range of movements. Patients functional recovery was assessed by means of Harris Hip Score in every visit.

\begin{tabular}{|c|c|}
\hline Duration & $\mathbf{2 0 1 2 - 2 0 1 4}$ \\
\hline No. of Patients & 15(M-9, F-6) \\
\hline Age & 25-62 years (avg-43) \\
\hline Mode of Injury & Fall(7), RTA(8) \\
\hline Type of Fracture & $\begin{array}{l}\text { IT fractures (A2(8), A3(3)) } \\
\text { subtroc fracture (4) type5 }\end{array}$ \\
\hline Side & $\mathrm{R}(10), \mathrm{L}(5)$ \\
\hline
\end{tabular}

\section{EXCLUSION CRITERIA:}

- Compound fractures.

- Stable trochanteric fractures.

- Neglected injuries.

- Fractures in skeletally immature.

- Polytrauma patients.

RESULTS: Closed reduction was achieved in 13 of the pertrochanteric fractures. Open reduction was done in 2 cases, both were subtrochanteric fractures with external rotation of proximal fragment. Short PFN was used in all the 11 intertrochanteric fractures and long PFN was used in 4 subtrochanteric fractures. The average operating time was $160 \mathrm{~min}(120-200 \mathrm{~min})$. Average blood loss is $500 \mathrm{ml}(100-1000 \mathrm{ml})$. In all patients both the cervical screws were inserted distally one locking screw was inserted in all short PFN cases and two screws were inserted in long PFN cases. Tip apex distance was kept to a minimum as described by Parker et al.6,7 Domingo ET et al reported $12 \%$ cases with operative difficulties.

In our series, one patient had circlage wiring done over the shaft due to splinter in the outer cortex at the distal locking site. One patient had serous oozing from the proximal locking site which subsided with wound lavage and hematoma evacuation. Nine patients were able to walk partial bearing with walker support by one week and the average hospital stay was 15 days ( 7 to 30 days). Average followup was for 11 months (3 mon. to 18 mon.) 
There were no wound related complications on follow up. All patients complained of pain in the upper lateral thigh on followup upto 3mon. Two patients with 18 months followup had persistent lateral thigh pain and anterior thigh pain due to excessive callous formation at the fracture site in subtrochanteric fractures with head injury. Abductor lurch was present in one patient. Average shortening of the affected limb was around $1 \mathrm{~cm}(1-2 \mathrm{~cm})$ which were managed without any shoe rise.

All the 15 patients were able to do full weight bearing by 3 months. 12 of the fifteen patients were able to squat and sit crosslegged on final followup. All 15 patients had complete union by 6 months of followup. The average fracture healing time is 3.5 months. Varus malalignment was present in one patient. One patient had a lower cervical screw back out which needed removal after healing.

\begin{tabular}{|c|c|}
\hline Avg Operating Time & 160min (120-200) \\
\hline Avg Blood Loss & $500 \mathrm{ml}(100-1000 \mathrm{ml})$ \\
\hline Avg Followup & $11 \mathrm{mon}(3-18 \mathrm{mon})$ \\
\hline Avg Healing Time & $3.5 \mathrm{mon}$ \\
\hline
\end{tabular}

Functional recovery of patients is assessed by means of Harris Hip Score.

\begin{tabular}{|c|c|}
\hline Harris Hip Score & No of patients \\
\hline $91-100$ & 1 \\
\hline $81-90$ & 11 \\
\hline $71-80$ & 4 \\
\hline$<70$ & NIL \\
\hline
\end{tabular}

DISCUSSION: Pertrochanteric fractures are common injuries around the hip. Surgical management places a vital role in their management.

In case of unstable pertrochanteric fractures, the options for fixation includes conventional implants like dynamic hip screw or dynamic condylar screw fixation. The conventional implants being load bearing devices are associated with problems ${ }^{8}$ like excessive collapse of proximal fragment and medialisation of distal fragment leading to problems of malunion and nonunion. These conventional implants cannot be used in unstable situations were the lateral wall integrity is compromised. Their longer moment arm leads to increased bending stress on the neck screws leading to increased rates of screw pull out and varus malunion.

Proximal femoral nails are load sharing implants with a shorter moment arm. With a larger diameter nail proximally they are associated with greater stability. ${ }^{9}$ Being an intramedullary implant, loss of integrity of the lateral wall of the proximal femur is not a limiting factor in using these implants. Inaddition, minimally invasive technique of insertion along with minimal blood loss ${ }^{10}$ and soft tissue dissection ${ }^{11}$ involved in the surgical technique with shorter operating time make proximal femoral nails as a promising member in the armamentarium of implants for fixing proximal femoral fractures. ${ }^{12}$

Innumerable studies were done to evaluate the results of proximal femoral nails in pertrochanteric fractures. Simmermacher et al reported complication rate of just $4.6 \%$ in 191 patients and no complications of fracture below the tip or bending or breakage of the implant were 
reported. J Pajarinen et $\mathrm{al}^{3}$ in their study of comparison between DHS and PFN found that the use of PFN has a positive effect on the better functional outcome primarily due to restoration of near normal anatomy as compared to DHS in which there is greater impaction of fracture leading to shortening of femoral neck. M. S. G. Ballal et al ${ }^{13}$ in their study found $5 \%$ failure rate and advocated proper alignment between 2 main fragments and proper placement of the lag screw in the femoral head. Cut-out of the implant was reported in one subject among a series of 46 fractures by Tyllianakis et al. ${ }^{14}$ in one out of 191 subjects by Simmermacher et al., in four out of 295 subjects by Domingo et al., in four out of 76 subjects by Alyassari. et al., in two out of 55 subjects by Boldin et al., 11 out of 211 subjects by Schipper et al.

Our retrospective study, shows good surgical results ${ }^{15}$ were well reproducible as in other series. Average limb length shortening postoperatively is also very much acceptable. Most of the complications which were encountered were due to technical faults which can be prevented by proper surgical planning and training. The strength of the study is that the data pertains to only fractures of proximal femur which are unstable. The drawbacks of this study are its retrospective nature, small sample size and shorter followup.

CONCLUSION: We conclude that proximal femoral nails serve as ideal implants for pertrochanteric fractures. with added advantages of shorter operating time and minimal blood loss, they help in early mobilisation of the patient and help in ensuring early return of operated patients to normal day to day activities.

\section{REFERENCES:}

1. GS Kulkarni, Rajiv Limaye, Milind Kulkarni, Sunil Kulkarni. Current Concept review Intertrochanteric fractures. Indian Journal of Orthopaedics. 2006 Jan; 40 (1): 16.

2. 2 GS Kulkarni, Rajiv Limaye, Milind Kulkarni, Sunil Kulkarni. Intertrochanteric fractures. Indian journal of Orthopaedics. 2008, 40: 1623.

3. J. Pajarinen, J. Lindahl, O. Michelsson, V. Savolainen and E. Hirvensalo, "Pertrochanteric Femoral Fractures Treated with a Dynamic Hip Screw or a Proximal Femoral Nail. A Randomized Study Comparing Post-Operative Rehabilitation, " Journal of Bone and Joint Surgery, Vol. 87, No. 1, 2005, pp. 76-81.

4. Vidyadhara S, Rao SK, one and two femoral neck screws with Intramedullary Nails for unstable trochantric fractures of femur in the eldrly -Randomised clinical trial. Injury2007; 38 (7): 806 814.

5. FritzT, Hiersemannk, Krieglstein C, Fried IW, Prospective randomized comparision of gliding Nail and Gamma Nail in the therapy of trochantric fractures. Arch orthop Trauma Surg 1999, 119 (1-2); 1-6.

6. Parker MJ. Cutting-out of the dynamic hip screw related to its position. J Bone Joint Surg Br. 1992; 74: 625.

7. Herman A. et al. Radiological evaluation of intertrochanteric fracture fixation by the proximal femoral nail. Injury, Int. J. Care Injured 43. 2012; 856-863.

8. Christian Boldin, Franz J. Seibert, Florian Fankhauser, Gerolf Peicha, Wolfgang Grechenig, et al. Proximal femoral nail (PFN) - A minimal invasive treatment of unstable proximal femoral fracture. Acta Orthopaedica 2003 Feb; 74 (1): 53-8. 


\section{ORIGINAL ARTICLE}

9. Brunner A, Jockel JA, Barbst R, The Proximal Femoral Nail Antirotation Proximal Femoral Nail in the treatement of unstable intertrochantric fractures-3 Cases of post-operative perforation of helical blade into the hip joint. J ortho Trauma 2008; (10): 731-36.

10. Radford P J, Needoff M, Webb J K. A prospective randomised comparison of the dynamic hip screw and the gamma locking nail. J Bone Joint Surg (Br) 1993; 75: 789-93.

11. McKibbin B. The biology of fracture healing in long bones. J Bone Joint Surg (Br) 1978; 60: 150 62.

12. Bucholz RW, Heckman JD, Koval KJ, Zukerman JD. Rockwood and Green's fractures in adults. 6th ed. Philadelphia: Lippincott Williams and Wilkins; 2005.

13. M. S. G. Ballal, N. Emms, M. Ramakrishnan and G. Thomas, "Proximal Femoral Nail Failures in Extracapsular Fractures of the Hip, " Journal of Orthopaedic Surgery, Vol. 16, No. 2, 2008, pp. 146-149.

14. Tyllianakis M, Panagopoulos A, Papadopoulos A, Papasimos S, Mousafiris K. Treatment of extracapsular hip fractures with the proximal femoral nail (PFN) : long term results in 45 patients. Acta Orthop Belg 2004; 70: 444-54.

15. Pavelka T, Houcek P, Linhart M, Matejka J. Osteosynthesis of hip and femoral shaft fractures using the PFN-long. Acta Chir Orthop Traumatol Cech. 2007 Apr; 74 (2): 91-8.

\section{CASE 1:}

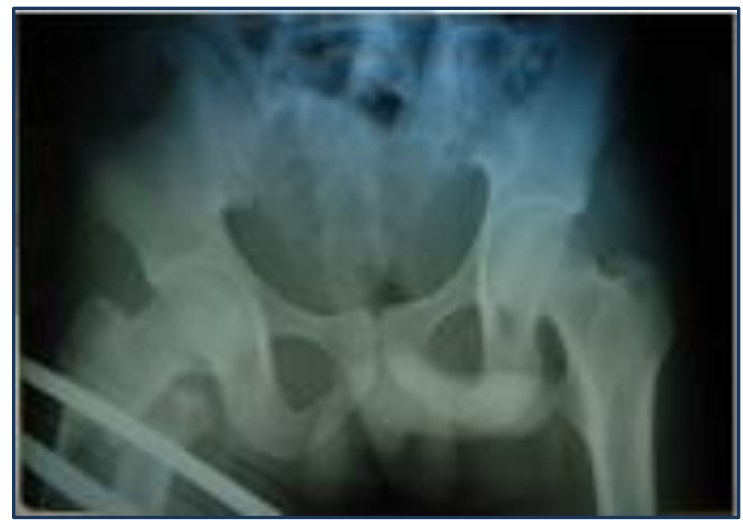

Pre OP
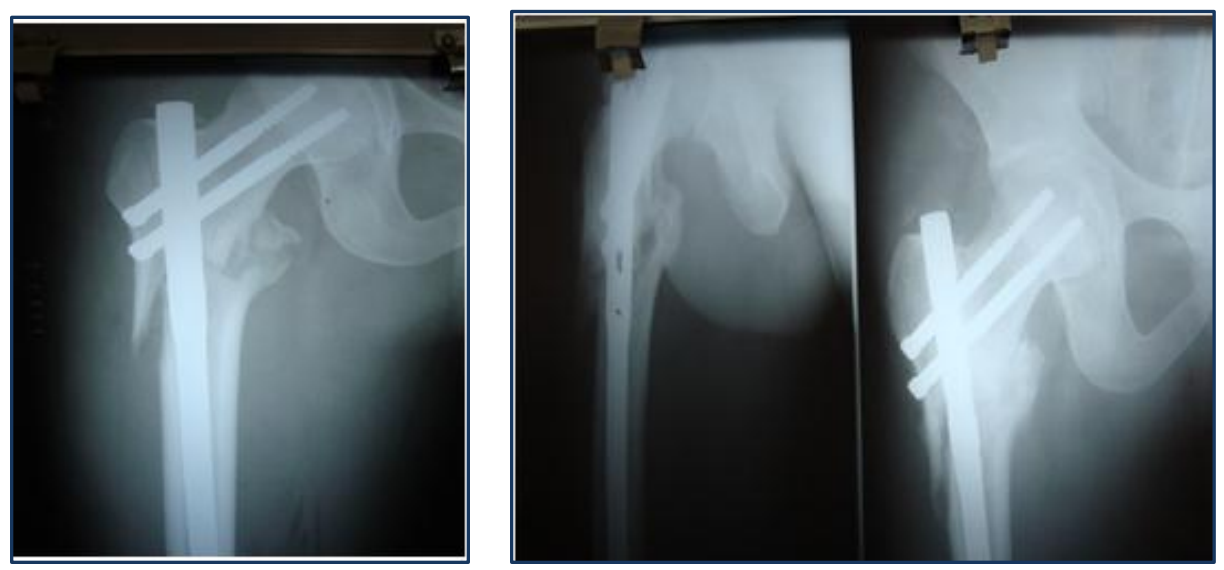

Post OP 


\section{ORIGINAL ARTICLE}

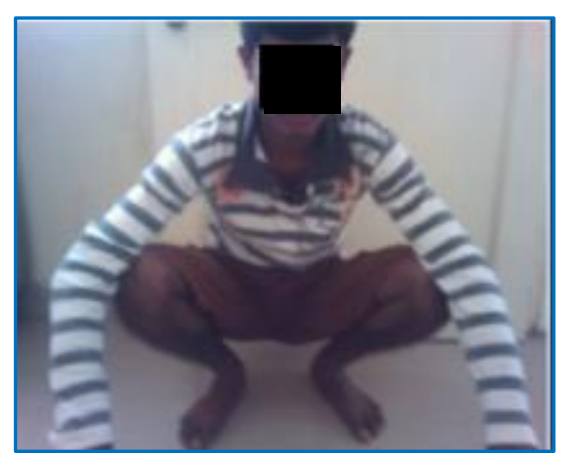

\section{CASE 2:}

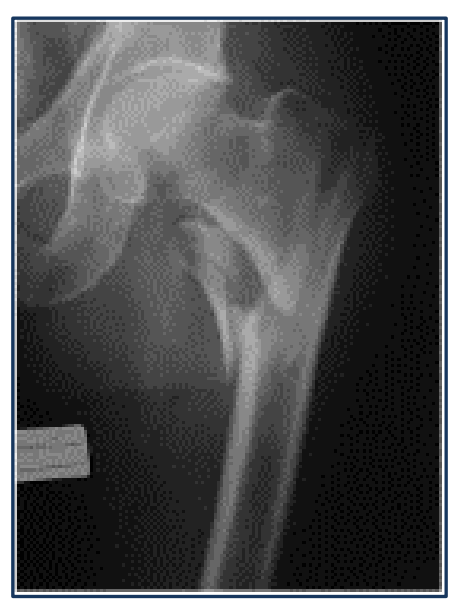

Pre OP

\section{CASE 3:}

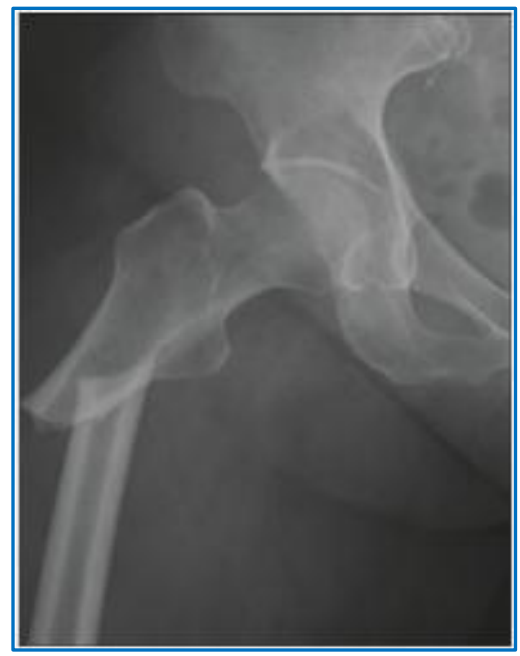

Pre OP
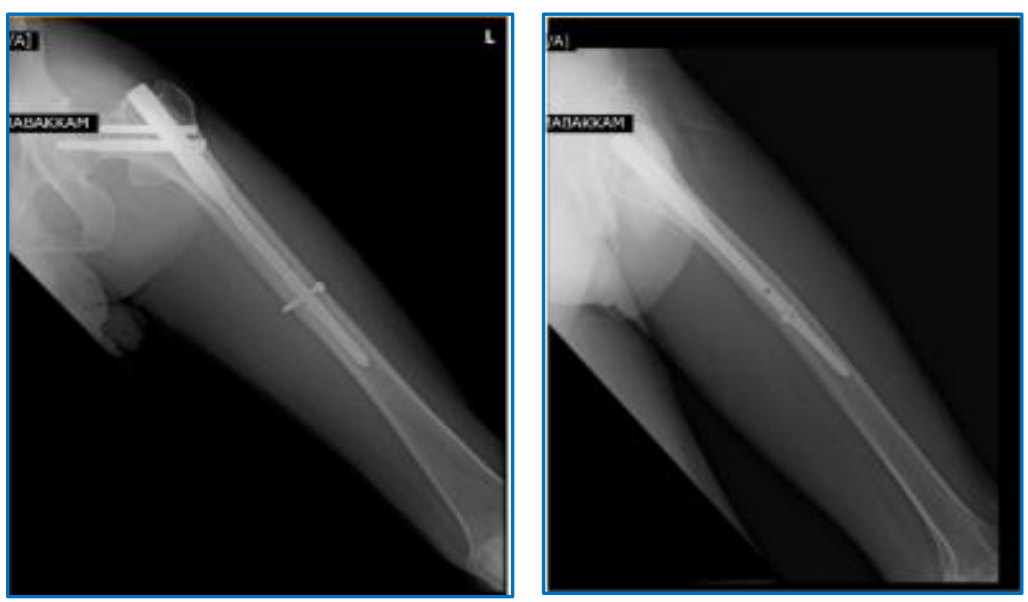

Post OP
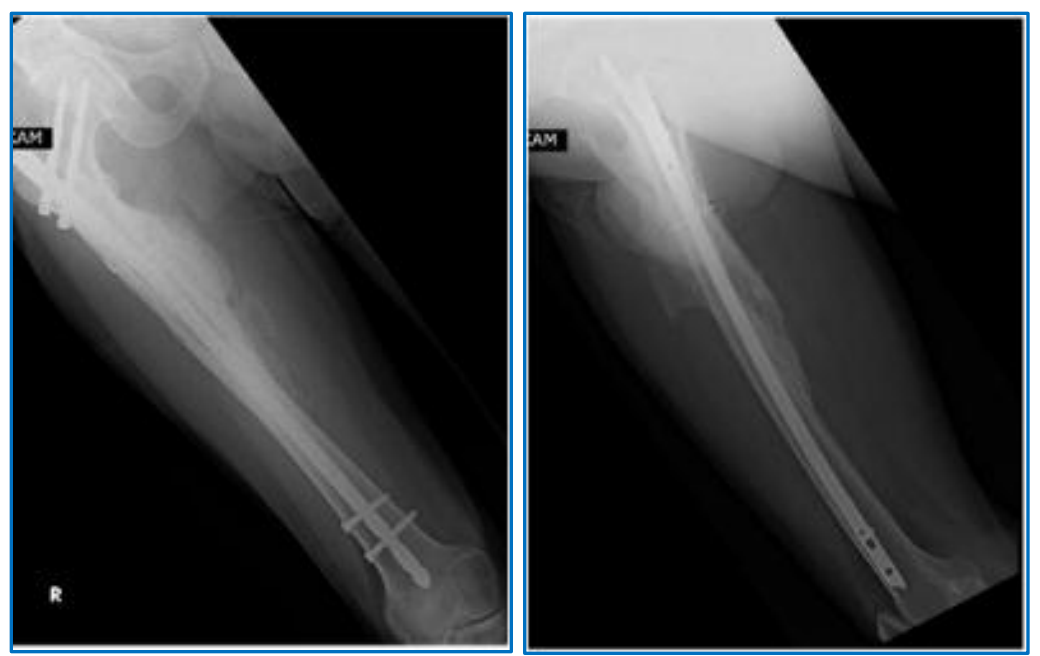

Post OP 


\section{ORIGINAL ARTICLE}

\section{AUTHORS:}

1. R. J. Bharat Kumar

2. Victor Moirangthem

3. M. Narayana Reddy

\section{PARTICULARS OF CONTRIBUTORS:}

1. Assistant Professor, Department of Orthopaedic Surgery, Chettinad Hospital and Research Institute, Kelambakkam.

2. Associate Professor, Department of Orthopaedic Surgery, Chettinad Hospital and Research Institute, Kelambakkam.

FINANCIAL OR OTHER

COMPETING INTERESTS: None
3. Professor \& H.O.D, Department of Orthopaedic Surgery, Chettinad Hospital and Research Institute, Kelambakkam.

\section{NAME ADDRESS EMAIL ID OF THE CORRESPONDING AUTHOR:}

Dr. R. J. Bharat Kumar, C 20, Deccan Pragati,

Zamin Pallavaram,

Chennai-600043.

E-mail: bharatortho82@gmail.com

Date of Submission: 04/05/2015.

Date of Peer Review: 05/05/2015.

Date of Acceptance: 20/05/2015.

Date of Publishing: 27/05/2015. 